1 Universidade Estadual do Centro-Oeste (Unicentro), Programa de Pós-

Graduação Interdisciplinar em Desenvolvimento Comunitário (PPGDC) Irati (PR), Brasil.

alcirhumberto@gmail.com

2 Universidade Estadual do Centro-Oeste (Unicentro), Programa de PósGraduação Interdisciplinar em Desenvolvimento Comunitário (PPGDC) Irati (PR), Brasil. fonoaudiologasuzelaine@ hotmail.com

3 Universidade Estadual do Centro-Oeste (Unicentro), Departamento de Psicologia - Irati (PR), Brasil.

reyxavier@gmail.com

\section{A saúde e seus significados para famílias fumicultoras da região de Irati (PR): contingências e contradições}

\author{
Health and its meanings to tobacco grower families of Irati $(P R)$ : \\ contingencies and contradictions
}

Alcir Humberto Rodrigues', Suzelaine Taize Stadler ${ }^{\mathbf{2}}$, César Rey Xavier ${ }^{\mathbf{3}}$

RESUMO A fumicultura é uma das principais atividades da região de Irati, entretanto provoca malefícios para a saúde. O objetivo foi compreender os significados de saúde e sua importância em famílias de fumicultores. Realizou-se observação participante e entrevistas com famílias. Optou-se pela análise de conteúdo, modalidade temática. Como resultados, revelaram-se os núcleos temáticos: 'O hábito de fumar e a saúde nas gerações das famílias', 'Dificuldades na utilização de Equipamento de Proteção Individual', 'Preocupação com a saúde infantil' e 'Saúde, cultura e economia: implicações da fumicultura'. A promoção da saúde dos fumicultores depende de ações intersetoriais.

PALAVRAS-CHAVE Cultura. Família. Saúde. Tabaco. Hábito de fumar.

ABSTRACT Tobacco growing is one of the main activities of the Irati region, however it causes harm to health. The objective was to understand the meanings of health and its implications for tobacco farming families. We conducted participant observation and interviews with families. We opted for content analysis, thematic modality. As a result, such thematic groups arose: 'Smoking and health in the generations of the families', 'Difficulties in the use of Personal Protective Equipment', 'Concern for child health', and 'Health, culture, and economy: implications of tobacco farming'. Health promotion directed at tobacco growers needs intersectional actions.

KEYWORDS Culture. Family. Health. Tobacco. Smoking. 


\section{Introdução}

A participação paranaense na produção brasileira de tabaco é de 19\% (PARANÁ, 2013; SINDITABACO, 2013), e o núcleo de Irati destaca-se por ser o maior produtor entre todos, respondendo por $26 \%$ do total da produção do estado (PARANÁ, 2013). Assim, a região de Irati tem na fumicultura uma das principais atividades agrícola, econômica e de trabalho, sendo cultivada em pequenas propriedades rurais, na forma de agricultura familiar. O plantio do fumo, seu manejo e o baixo valor agregado do produto, associado ao uso intenso de agrotóxicos e à falta de práticas preventivas pelos fumicultores, trazem prejuízos para a comunidade. Os danos atingem diversas esferas, entre elas a saúde, a educação formal, a renda e o ambiente.

O cultivo de tabaco é fisicamente exigente, com movimentação manual de cargas pesadas e aplicação de uma variedade de agrotóxicos em diferentes fases, tais como a pulverização de brometo de metila (herbicida, inseticida, fungicida e nematicida) durante a produção de mudas, disulfoton (organofosforado inseticida e acaricida) após semeadura e transplante e imidacloprid (nitroguanidina inseticida) e acefato (organofosforado inseticida e acaricida) para controle de pragas até a colheita. É bem sabido que a utilização desses produtos provoca vários problemas de saúde e danos ambientais. A ocorrência de transtornos mentais, como depressão crônica e suicídio, está entre as consequências geradas pela intoxicação crônica por pesticidas organofosforados (RIQUINHO; HENNINGTON, 2012).

Ainda, entre os problemas de saúde, destaca-se o envenenamento por nicotina, conhecido como doença da folha verde do tabaco, sentida durante a colheita do fumo. A doença da folha verde do tabaco é resultante da exposição dérmica às folhas que provoca intoxicação aguda por nicotina, com sintomas que incluem náuseas, vômitos, dor de cabeça e cólicas abdominais (MCBRIDE ET AL., 1998).
De modo geral, as políticas públicas têm sido pouco eficazes no sentido de lidar com a vulnerabilidade da saúde acarretada pela fumicultura, reafirmando práticas assistencialistas, de caráter paliativo, que terminam por mascarar as questões estruturais da dinâmica social. Na região de Irati, a fumicultura ocupa um espaço que ultrapassa as questões relacionadas com a saúde, estendendo-se às questões culturais e ao estilo de vida. Atualmente, verifica-se um movimento no sentido de estimular a diversificação da produção ante a prevalência da monocultura do tabaco, no intuito de substituir ou diminuir gradualmente o trabalho com o fumo e, consequentemente, melhorar as condições de saúde de seus produtores bem como do meio ambiente. No entanto, esse movimento tem se deparado com inúmeras barreiras.

Diante dessa realidade, o objetivo do presente estudo foi compreender os significados da saúde e a sua importância em famílias de fumicultores da região de Irati. Vale ressaltar que o presente artigo leva em conta não apenas o conteúdo extraído de suas falas, das observações ou de alguns parâmetros já estabelecidos por autores que discutem esta temática. O presente estudo aqui realizado procurou também considerar contingências, não raro dramáticas, que circunscrevem o cotidiano de vida e de trabalho dos fumicultores entrevistados, atrelados aos significados da saúde para suas vidas. Nestas, é possível vislumbrar certas nuanças de um contexto que explica, às vezes por si só, algumas atitudes aparentemente contraditórias.

\section{Metodologia}

Trata-se de um estudo descritivo, de caráter qualitativo. Para a coleta de dados, foi realizada observação participante e entrevista aberta, com duas famílias de Irati (PR) e região. A coleta de dados ocorreu no período de janeiro a março de 2015, na região de Irati, estado do Paraná, durante o período de colheita do fumo. 
A amostra foi estabelecida por conveniência. As famílias estudadas foram selecionadas por estarem em busca de cultivos alternativos à fumicultura. As observações foram anotadas em diário de campo. Já as falas obtidas por meio das entrevistas foram gravadas em áudio, com a autorização dos participantes e, posteriormente, integralmente transcritas. As falas foram lidas exaustivamente, e, para análise, realizou-se análise de conteúdo, modalidade temática (MINAYO, 2006).

A primeira família era composta pelo pai, pela mãe, por uma filha adolescente de 13 anos e pelo o avô que residia com a família. A segunda família tinha como membros o pai, a mãe e dois filhos, sendo um adolescente de 12 anos e outro com 2 anos de idade. Os pais e mães, das duas famílias, tinham idade entre 30 e 40 anos. Para preservar o anonimato dos participantes, eles foram identificados como P1, P2 e assim sucessivamente.

O projeto foi aprovado no Comitê de Ética em Pesquisa da Unicentro, com o número do parecer 655.538/CAAE: 30615614.3.0000.0106, em 20/05/2014.

\section{Resultado e discussão}

As falas foram analisadas, e os conteúdos foram agrupados em quatro núcleos temáticos, sendo eles: 'O hábito de fumar e a saúde nas gerações das famílias', 'Dificuldades na utilização de Equipamento de Proteção Individual', 'Preocupação com a saúde infantil' e 'Saúde, cultura e economia: implicações da fumicultura'.

\section{O hábito de fumar e a saúde nas ge- rações das famílias}

Durante a observação participante, foi verificado que nenhum dos participantes apresentava o hábito de fumar. Tal fato chamou bastante atenção visto que, ao serem indagados durante as entrevistas, os participantes revelaram que seus pais eram fumantes, mas que eles próprios abandonaram o hábito devido à percepção de que tal prática debilitava a saúde. Revelaram ainda que os filhos não se interessaram pelo hábito de fumar.

Antigamente quando a gente plantava também costumava fumar. Depois de um tempo a saúde ficou ruim daí vimos que o melhor era parar [de fumar], daí paramos. Mas ainda bem que os fiIhos da gente não tinham muita vontade de fazer isso, daí não começaram que nem nós fizemos. Eu cheguei a fumar uns 18 anos, ainda bem que parei; inclusive com a plantação... [risos]! (P1).

Eu não gosto de cigarro, nem do cheiro do fumo. (P2).

Quando se analisa os discursos, nota-se que a primeira geração de fumicultores, a qual iniciou e introduziu o plantio de tabaco na região de Irati, possuía o hábito de fumar, porém de forma peculiar como nos revela a fala a seguir:

Aqui em casa só o pai fumava, mas não cigarro comprado... fumava cigarro de fumo que ele plantava no quintal, que era mais puro, sem veneno né? (P2).

Percebe-se que o hábito de fumar estava relacionado com o consumo do fumo in natura, ou seja, de cigarros caseiros e feitos com fumo plantado no quintal, sem a presença de agrotóxicos. Nota-se ainda que as gerações posteriores, especificamente segunda e terceiras gerações, não praticam o hábito de fumar alegando para isso os prejuízos que este provoca ao seu estado de saúde.

Deus o livre... já não chega trabalhar com fumo, ainda fumar? Não tem saúde que aguente... (P3).

Nem fumar e nem trabalhar no fumo... depois que tive as crianças fico só em casa, só ajudo na hora de classificar [o fumo]... (P4). 
Em estudo realizado com fumicultores da região de São Lourenço do Sul (RS) (FASSA ET AL., 2014), é apontado que o número de agricultores não fumantes é muito maior que o de tabagistas, sendo essa diferença mais acentuada entre as mulheres. Tal estudo soma-se à inferência de que, diante das constatações com as duas famílias aqui pesquisadas, a consciência dos malefícios gerados com o fumo passou a pesar mais do que o hábito ainda arraigado da antiga geração, não obstante terem no fumo seu trabalho e sustento. Em outras palavras, é possível constatar que trabalhar na fumicultura não é fator determinante para ser fumante.

Percebe-se, então, uma preocupação com o cuidado de si, entendido como aquele que possui uma complexa rede de significados e relações, envolvendo o autoconhecimento e a atenção à própria saúde (SILVA ET AL., 2013A). Entende-se, portanto, que este 'cuidado de si', intrínseco à decisão de abandonar o hábito de fumar no contexto das duas famílias, demonstra que os fumicultores são capazes de perceber e tomar consciência dos malefícios causados à sua saúde, apesar de não possuírem todo o saber científico a respeito do tabagismo e suas implicações. Os participantes demonstram, portanto, que são protagonistas de suas práticas a partir do conhecimento, que embora não seja científico, é um conhecimento legítimo e válido, imbricado com suas concepções de vida e cultura (SANTOS, 2010).

\section{Dificuldades na utilização de Equipa- mento de Proteção Individual}

Durante as observações realizadas na colheita do fumo, não foi observada a adoção de medidas de proteção coletiva. Pode-se perceber também que os fumicultores não utilizavam os Equipamentos de Proteção Individual (EPI). Nas entrevistas, os participantes revelaram que a não utilização é motivada por diversos fatores. Entre eles, o mais mencionado é a dificuldade do uso do equipamento, que muitas vezes são projetados para países com clima diferente do apresentado na região sul do Paraná. Esses equipamentos muitas vezes são adaptados, 'aclimatados' ao manejo local e por isso mesmo não são perfeitamente adequados às condições de uso do fumicultor do Sul do Brasil. Durante as observações, constatou-se o intenso calor durante a colheita e as dificuldades práticas na falta de adesão à utilização do equipamento de proteção.

Já viu o calor que fica dentro da roupa? É impossível usar toda aquela rouparada [para colher o fumo]. (P4).

Com a luva eu não consigo sentir a folha [do fumo], só atrapalha. (P5).

O pai nunca usou nada destas coisaradas... aprendi com ele, não me acostumo de jeito nenhum [com o uso dos EPI]. (P5).

Pra falar a verdade, a gente só usa quando o fiscal vem fazer visita. (P4).

Os resultados apresentados chamam a atenção para um aspecto importante a ser refletido: como exigir a utilização do EPI em condições climáticas extremamente desfavoráveis? Ainda, como lidar com a alegação do conhecimento adquirido 'de pai para filho' e modificar um comportamento valorizado culturalmente?

A literatura menciona que o cuidado de si é relevante para a saúde desses trabalhadores e para o seu processo de trabalho, pois as ações desenvolvidas para a manutenção desse cuidado melhoram a qualidade de vida pessoal e profissional (FERREIRA ET AL., 2015), entretanto não é isso que é praticado entre os fumicultores de modo geral (RIQUINHO; HENNINGTON, 2014).

Silva et al. (2013B) afirmam que, a partir de 
pesquisa realizada na zona rural de Pelotas (RS), constatou-se que os fumicultores possuem um conhecimento pouco profundo em relação aos problemas de saúde aos quais são expostos no seu ambiente laboral. Afirmam, também, que os EPIs são pouco aceitos pelos fumicultores e que estes fazem uso somente de alguns dos equipamentos, por considerarem desconfortáveis. Os autores do estudo apontam que, associado a esta realidade, existe uma falta de capacitação dos agricultores que plantam o tabaco na região e concluem que há a necessidade de um trabalho educativo nas lavouras de fumo.

Os agravos causados pela cultura do tabaco e seus significados também são descritos por famílias de agricultores em localidade rural do estado do Rio Grande do Sul. Além disso, no estado gaúcho, ficou evidenciado o reconhecimento da presença da doença da folha verde do tabaco e outros agravos por parte dos agricultores e representantes da sociedade civil (RIQUINHO; HENNINGTON, 2014).

Em se tratando dos resultados do presente estudo, verificou-se que os participantes conhecem, sim, as implicações da fumicultura para a sua saúde, não a partir de um aprofundamento do conhecimento técnico científico, mas sim de suas práticas e vivências. A alegação do não uso do EPI devido ao desconforto causado por ele é legitima e deve ser considerada como um desafio a ser enfrentado. Convém mencionar que a falta da adoção de medidas de proteção coletiva pode estar atrelada a fumicultura em si mesma. Nesse caso, o fumicultor está exposto a riscos tecnicamente não controláveis por medidas coletivas de proteção ou ainda, quando adotadas, as medidas coletivas de controle adotadas atuam de forma apenas parcial (COUTO, 1998).

Outro fato que chama a atenção é a preocupação com o uso do EPI somente quando ocorre a fiscalização realizada pelos técnicos da indústria fumageira, como revela a fala acima. Na realidade, a indústria fumageira controla todos os aspectos do cultivo do fumo, mas não se responsabiliza pela saúde dos fumicultores, tampouco assume os riscos inerentes ao cultivo do fumo (ALMEIDA, 2005).

\section{Preocupação com a saúde infantil}

É notório que, das falas coletadas, emerge a grande preocupação das famílias com a saúde infantil. Em uma das famílias entrevistadas, os pais afirmaram que seus dois filhos não participam do processo de produção e seleção do tabaco.

A gente sabe que faz mal né? Tem até caveirinha nas embalagens [dos agrotóxicos]... você acha que vou querer mal pro meu filho? (P4).

Desde que eles estavam na barriga. Sabendo que eu estava de barriga, eu já não ia lidar com o fumo pra não prejudicar a saúde deles [dos fiIhos]. (P4).

Nota-se, portanto, que esses pais têm consciência de que a fumicultura possui implicações para a saúde de seus filhos, seja pela exposição às folhas do tabaco, seja pela exposição ao agrotóxico empregado em sua produção. Essa percepção dos prejuízos tem corroboração na literatura contemporânea (RIQUINHO; HENNINGTON, 2014). Crianças expostas ao tabagismo apresentam maior risco de desenvolver otites, sibilo, coriza e irritação ocular que as não expostas (COELHO; ROCHA; JONG, 2012). Ainda, o tabagismo passivo pode até prejudicar o quociente de desenvolvimento de linguagem superior, isto é, o desenvolvimento psicomotor da primeira infância (SANTOS; COSTA, 2015).

Quando P. era pequeno foi muito difícil... ele vivia doente. Eu ia pra Curitiba todo mês, fiquei anos indo lá [no Hospital de Clínicas]... Ele tinha uma tosse que não terminava... e um problema na pele. E o engraçado é que aqui em casa ninguém fumava! (P4). 
O tabagismo durante a gestação tem implicações que vão além dos prejuízos à saúde materna (HSS; CDC, 2010). Os malefícios sobre a saúde fetal são tantos, que justificam dizer que o feto é um verdadeiro fumante ativo (LEOPÉRCIO; GIGLIOTTI, 2004). O fumo na gravidez é responsável por $20 \%$ dos casos de fetos com baixo peso ao nascer, $8 \%$ dos partos prematuros e $5 \%$ de todas as mortes perinatais (CDC, 1990). Estudos mostram que o tabagismo na gestação pode contribuir para a Síndrome da Morte Súbita Infantil, além de causar importantes alterações no desenvolvimento do sistema nervoso fetal (LAMBERS; CLARK, 1996).

Bebês nascidos de mulheres que fumam durante a gravidez têm cerca de $30 \%$ mais probabilidades de nascerem prematuramente. São mais propensos a nascer com baixo peso (menos de 2.500 gramas), aumentando seu risco de doença ou morte, e pesar uma média de 200 gramas a menos do que crianças nascidas de mulheres que não fumam. Também são 1,4 a 3,0 vezes mais predispostos a morrer de Síndrome da Morte Súbita Infantil (HSS; CDC, 2007).

O tabagismo materno no início da gravidez tem sido casualmente associado a fendas orofaciais e gravidez ectópica (HSS, 2014A). A gravidez ectópica é uma condição na qual o óvulo fertilizado não consegue alcançar o útero e, como alternativa, anexa-se à trompa de Falópio ou a outros órgãos fora do útero. A gravidez ectópica quase sempre causa a morte fetal e representa um risco grave para a saúde da mãe (HSS, 2014B).

Mulheres que fumam durante a gravidez têm duas vezes mais probabilidade de sofrer ruptura prematura de membranas, descolamento prematuro da placenta e placenta prévia. Ainda, as mulheres grávidas que estão expostas ao fumo passivo têm chances $20 \%$ maiores de dar à luz um bebê de baixo peso do que as mulheres que não estão expostas ao fumo passivo durante a gravidez (HSS; CDC, 2007).

Não obstante os relatos em que ficaram patentes as preocupações com a saúde das crianças, verificou-se, durante as observações, que os filhos das duas famílias convivem e brincam nos espaços reservados à área de manuseio do tabaco, fato que denota certa contradição com as falas anteriores. Foram vistos brinquedos no pátio de classificação do fumo e roupas de cama infantis no quarto próximo a estufa. Tais observações foram confirmadas nas falas abaixo.

As crianças não trabalham com o fumo, mas ficam aqui perto da gente quando o serviço apura, né? (P4).

Quando o pai vai cuidar da estufa [durante a noite] vem todo mundo junto pra ele não ficar sozinho. (P6).

Diante da contradição entre as falas e as observações, questiona-se se realmente não há a participação das crianças no trabalho com o fumo. A literatura menciona que, entre 1970 e 2000 , ocorreu um fenômeno de transferência da produção de tabaco dos países desenvolvidos, especificamente Estados Unidos, União Europeia e Japão, para os que estão em desenvolvimento, tais como o Brasil, motivados pela diminuição dos subsídios governamentais, aumento no controle do tabagismo e, consequentemente, custos de produção e diminuição dos lucros do tabaco (RIQUINHO; HENNINGTON, 2012).

Nesses países, a força de trabalho do tabaco tem sido geralmente constituída por mulheres, negros e imigrantes e é caracterizada por mão de obra de remuneração mais baixa. Também se observa a presença do trabalho infantil em todos os países com plantio operado por famílias, com crianças que trabalham em tempo integral, ou durante o horário não escolar, com participação em todo o processo de cultivo do fumo (RIQUINHO; HENNINGTON, 2012).

Ressalte-se ainda que a fumicultura praticada na região de Irati é constituída como agricultura familiar. Menezes e Magalhães 
(1998) relatam que, no sistema de produção familiar, os agricultores envolvem os próprios filhos no cultivo do fumo, sendo um misto de necessidade e cultura. Como o período da safra coincide com as férias escolares, crianças e adolescentes são expostos em contato direto com agrotóxicos e nicotina durante a colheita e secagem do fumo. Dessa forma, aponta-se aqui a relevância de que novos estudos sejam realizados para verificar se na realidade local ocorre ou não o emprego da mão de obra infantil no cultivo do tabaco.

\section{Saúde, cultura e economia: implica- ções da fumicultura}

Como mencionado anteriormente, as famílias participantes do estudo encontram-se em um processo de busca de alternativas para o trabalho na fumicultura.

Já tentaram morango, mel, pêssego... mas não adianta... é difícil sair do fumo... (P4).

Você faz tudo certinho... daí o vento vem e traz todo o veneno da plantação do lado... está perdido todo o seu trabalho [no cultivo do tabaco orgânico]. (P5)

Entretanto, percebe-se que tal processo tem esbarrado em alguns desafios, e o principal deles é a dependência econômica que as famílias possuem da indústria do tabaco, já que esta subsidia em grande parte a economia daquelas. Junte-se a esse fato a experiência de certo status conquistado a partir de bens de consumo e renda adquiridos pelas famílias fumicultoras, o que sugere um aumento da autoestima que parece superar as preocupações com a sua saúde, como se pode verificar nas falas a seguir.

Chamam a gente de sujo, de fedido, de fumeiro, mas quem tem dinheiro pra fazer compra no comércio? Somos nós... (P4).
Quando vamos à cidade, todo mundo do comércio vem puxar pro nosso lado porque sabem que temos dinheiro para comprar, para pagar... (P4).

Tem que ser um serviço muito bom pra ter renda igual ao fumo... A gente sofre, fica doente, mas vale o sacrifício... (P5).

Minha casa, carro... eu só tenho graças ao fumo... (P3).

Diante das falas, é interessante constatar que, para as famílias, são nítidas as implicações que a fumicultura provoca em sua saúde. Por outro lado, apesar dessas implicações, as famílias sentem-se valorizadas socialmente com a 'recompensa' financeira e econômica proporcionada pelo cultivo do fumo. Pinheiro e Luz (1998) relatam que o fumicultor já está irremediavelmente atrelado ao esquema imposto pela indústria fumageira. Segundo os autores, os fumicultores reconhecem que estão intoxicados e com suas vidas e a de seus filhos, seriamente comprometidas. No entanto, não acreditam que seja possível produzir sem esta relação opressiva e nem sequer acreditam que existem alternativas. Nas palavras dos autores, os fumicultores "[...] submetem-se. E a ideologia do dominador passa a ser a visão do dominado. Infelizmente, este é o auge da servidão" (PINHEIRO; LUZ, 1998, P. 155).

Ao se aplicar mais profundamente as palavras dos autores acima sobre a realidade dos entrevistados nesta pesquisa, há que se refletir sobre até que ponto a consciência dos malefícios à saúde pode fazer frente à ideologia de dominação, assimilada pelos fumicultores. Em uma rápida metáfora, poder-se-ia compará-la mesmo à própria intoxicação gerada pelo contato com o fumo, pois se, por um lado, ocorre a intoxicação nos corpos que trabalham, por outro, a 'intoxicação ideológica' acomete a própria visão de mundo dos fumicultores, afetando desde sua vida social 
até a tolerância que desenvolvem pela debilidade de suas saúdes.

Irati e região fazem parte do chamado 'corredor da fome' do estado do Paraná, sendo também chamado de 'Paraná Pobre'. Apresenta índices preocupantes relacionados com o Índice de Desenvolvimento Humano, sendo 0,617 na década passada (PNUD, 2013), considerado baixo em relação às demais regiões do estado. A renda salarial das famílias é bastante baixa quando comparada às demais regiões, assim como a diversificação de vagas de emprego.

É fácil perceber que, nesse contexto, a fumicultura ocupa um lugar "valorizado' econômica e culturalmente. Torna-se difícil para as famílias fumicultoras visualizarem o quanto estão sendo exploradas pela indústria do tabaco e quais são as reais dimensões das implicações da fumicultura para a sua saúde. Essas dificuldades apontam para a necessidade de se desenvolverem novos estudos e de ações sinérgicas a essas famílias, especialmente no processo árduo imbricado na busca de novas alternativas à fumicultura.

\section{Considerações finais}

É interessante constatar, a partir destas impressões, que o universo dos fumicultores é carregado de contingências e contradições. Se por um lado apresentam bastante consciência dos riscos e malefícios à sua saúde provocados pelo fumicultura, por outro, demonstram dificuldades em diversificar sua produção. Estão atentos aos riscos do fumo aos seus filhos, mas ao mesmo tempo são complacentes com a proximidade destes nos locais de manejo do tabaco.

Trata-se de uma realidade complexa, que envolve algo mais do que uma fórmula imediatista, que se apresente com o intuito de resolver a contento todas as consequências desse modo de subsistência. Nesse modo de vida, estão imbricados não apenas um trabalho que gera renda para o sustento da família. Nas entrelinhas desse ofício, está presente também uma história familiar que atravessa gerações e uma renda que, de longe, representa uma condição digna de vida, chegando a superar as expectativas da média salarial da região. Enfim, todos esses fatores devem ser levados em conta quando se pretende compreender a saúde dos fumicultores e qual a importância que eles atribuem para ela. Além disso, os achados do presente estudo são importantes para que se planejem estratégias para modificar essa realidade e promover a saúde dos fumicultores. Nesse sentido, esta pesquisa indicou que, para além das ações educativas aos fumicultores, é imperativo um esforço que venha ao encontro de modificar as condições de trabalho desses profissionais, bem como a criação de soluções em que os próprios fumicultores sejam protagonistas de suas ações.

Fica clara a necessidade imperativa de que as ações em saúde dirigidas aos fumicultores devem prever o envolvimento de todos os atores sociais, a fim de que tais ações sejam legítimas e efetivas. A fumicultura é uma prática cuja análise é complexa e, como tal, demanda por enfoques que façam jus a tal complexidade, que levem em conta o conjunto inseparável de saúde, economia e cultura, ou seja, de ações intersetoriais.

Enfim, dentre todos os aspectos que esta pesquisa pode verificar, destaca-se a necessidade premente de que as ações promovidas pela indústria fumageira possam ser dirigidas, em algum momento futuro, para além da mera fiscalização, no sentido de estar com os fumicultores na busca de soluções efetivas e eficazes para a proteção da sua saúde.

\section{Colaboradores}

Alcir Humberto Rodrigues contribuiu substancialmente para a concepção, o planejamento, a coleta, a análise e a interpretação 
dos dados, bem como na construção e revisão crítica do conteúdo. Suzelaine Taize Stadler participou da coleta de dados e da aprovação da versão final do manuscrito. César
Rey Xavier contribuiu com a interpretação dos dados, na revisão crítica do conteúdo, bem como na construção da versão final do manuscrito.

\section{Referências}

ALMEIDA, G. E. G. Fumo: servidão moderna e violação de direitos humanos. Curitiba: Terra de Direitos, 2005

CENTERS FOR DISEASE CONTROL (CDC). Health benefits of smoking cessation. Jama, Rockville, v. 264, n. $15,1990$.

COELHO, S. A.; ROCHA, S. A.; JONG, L. C. Consequências do tabagismo passivo em crianças. Ciência Cuidado e Saúde, São Paulo, v. 11, n. 2, p. 294301, 2012.

COUTO, J. L. V. Riscos de acidentes na zona rural. Rio de Janeiro: UFRRJ, 1998.

FASSA, A. G. et al. Green tobacco sickness among tobacco farmers in southern Brazil. American Journal of Industrial Medicine, Pelotas, v. 57, n. 6, p. 726-735, 2014.

FERREIRA, E. S. et al. A relevância do cuidado de si para profissionais de enfermagem. Cienc. Cuid. Saude, Rio de Janeiro, v. 14, n. 1, p. 978-985, 2015.

LAMBERS, D. S.; CLARK, K. E. The maternal and fetal physiologic effects of nicotine. Seminars Perinatology, Ohio, v. 20, p. 115-126, 1996.

LEOPÉRCIO, W.; GIGLIOTTI, A. Tabagismo e suas peculiaridades durante a gestação: uma revisão crítica.
J Bras Pneumol., São Paulo, v. 30, n. 2, p. 176-185, 2004.

MCBRIDE, J. S. et al. Green tobacco sickness. Tobacco Control, Winston, v. 7, n. 3, p. 294-298, 1998.

MENEZES, C. C.; MAGALHÃES, E. M. Crianças e adolescentes na fumicultura/RS: trabalho, escola, saúde. Porto Alegre: Ministério do Trabalho, 1998.

MINAYO, M. C. S. O desafio do conhecimento: pesquisa qualitativa em saúde. São Paulo: Hucitec, 2006.

PARANÁ. Secretaria de Estado da Agricultura e do Abastecimento. Departamento de Economia Rural. Fumo: análise da conjuntura agropecuária (PR). Curitiba, nov. 2013. Disponível em: <http:// www.agricultura.pr.gov.br/arquivos/File/deral/ Prognosticos/fumicultura_2013_14.pdf>. Acesso em: 2 set. 2015 .

PINHEIRO, S.; LUZ, D. Ladrões de natureza: uma reflexão sobre a biotecnologia e o futuro do planeta. Porto Alegre: Fundação Juquira-Candiru, 1998.

PROGRAMA DAS NAÇÕES UNIDAS PARA O DESENVOLVIMENTO (PNUD). Atlas do Desenvolvimento Humano do Brasil: Irati, PR. 2013. Disponível em: <http://www.atlasbrasil.org.br/2013/ pt/perfil_m/irati_pr>. Acesso em: 8 set. 2015. 
RIQUINHO, D. L.; HENNINGTON, E. A. Health, environment and working conditions in tobacco cultivation: a review of the literature. Ciênc. Saúde Coletiva, Rio de Janeiro, v. 17, n. 6, p. 1587-1600, 2012.

Tobacco cultivation in the south of Brazil: green tobacco sickness and other health problems. Ciênc. Saúde Coletiva, Rio de Janeiro, v. 19, n. 12, p. 4797-4808, 2014.

SANTOS, B. S. Um discurso sobre as ciências. 7. ed. São Paulo: Cortez, 2010.

SANTOS, N. F.; COSTA, R. A. Parental tobacco consumption and child development. Jornal de Pediatria, Rio de Janeiro, v. 91, n. 4, p. 366-372, 2015.

SILVA, A. A. et al. Enfermagem e cuidado de si: percepção de si como corpo existencial no mundo. Revista Enfermagem UERJ, Rio de Janeiro, v. 21, n. 3, p. 366-370, 2013a.

SILVA, J. B. et al. Fumicultores da zona rural de Pelotas (RS), no Brasil: exposição ocupacional e a utilização de equipamentos de proteção individual (EPI). Saúde debate, Rio de Janeiro, v. 37, n. 97, p. 347-353, 2013 b.

\section{SINDICATO INTERESTADUAL DA INDÚSTRIA}

DO TABACO (SINDITABACO). Tabaco no Sul

do Brasil: tradição e renda, 2013. Disponível em: <http://sinditabaco.com.br/wp-content/ uploads/2013/03/12620_2013_arquivo_pdf_relatorio_ tabaco_sul_brasil_2013.pdf>. Acesso em: 2 set. 2015.

\section{U. S. DEPARTMENT OF HEALTH AND HUMAN}

SERVICES (HSS). The health consequences of

smoking: 50 years of progress. A report of the surgeon general. Atlanta, 2014a. Disponível em: <http://www. surgeongeneral.gov/library/reports/50-years-ofprogress/full-report.pdf >. Acesso em: 26 out. 2016.

Let's make the next generation tobacco-free: your guide to the 50th anniversary surgeon general's report on smoking and health. Atlanta, 2014b. Disponível em: <http://www.surgeongeneral.gov/library/reports/50years-of-progress/consumer-guide.pdf $>$. Acesso em: 26 out. 2016.

\section{U. S. DEPARTMENT OF HEALTH AND HUMAN SERVICES (HSS); CENTERS FOR DISEASE CONTROL AND PREVENTION (CDC). A Report of} the surgeon general: how tobacco smoke causes disease. Atlanta, 2010. Disponível em: <https://www.cdc.gov/ tobacco/data_statistics/sgr/2010/consumer_booklet/ pdfs/consumer.pdf>. Acesso em: 26 out. 2016.

Preventing smoking and exposure to secondhand smoke before, during, and after pregnancy. Atlanta, 2007. Disponível em: <http://www.ctparenting.com/_files_/ smoking.pdf>. Acesso em: 26 out. 2016.

\footnotetext{
Recebido para publicação em maio de 2016

Versão final em setembro de 2016

Conflito de interesses: inexistente

Suporte financeiro: Coordenação de Aperfeiçoamento de Pessoal de Nível Superior (Capes), com bolsa do Programa Nacional de Pós-Doutorado (PNPD/Capes)
} 